\title{
Cuarenta años
}

\section{y se mantiene la ilusión}

$\mathrm{H}$

ace cuatro décadas, los jóvenes de entonces no soñábamos con que Aguascalientes contara con una universidad, ni pública ni privada. Los egresados de la preparatoria, en 1970, no teníamos más que tres caminos: 1) Emigrar hacia las principales ciudades de México e inscribirnos en una universidad. 2) Permanecer en Aguascalientes y cursar una de las dos primeras licenciaturas que impartía el Instituto Autónomo de Ciencias y Tecnología (IACT). 3) Suspender los estudios y dedicarse a buscar un trabajo.

Desde luego que las condiciones de Aguascalientes eran total y absolutamente diferentes a las que conocemos hoy en día, por lo que bien vale la pena ilustrar a los jóvenes estudiantes y a los académicos mencionando que el Aguascalientes que teníamos entonces ofrecía una multiplicidad de rostros, pero definitivamente no tan complejo como vemos en la actualidad.

Bien merece conocer algunas cifras que predominaban en ese pasado todavía no tan remoto, como pudieran pensar algunos. En el censo oficial aplicado el 28 de enero de 1970, el estado de Aguascalientes tenía 338 mil 142 habitantes, de los cuales 167 mil 309 eran hombres y 170 mil 833 eran mujeres, distribuidos en nueve municipios, en donde la capital tenía a la mayoría de habitantes con 224 mil 535 ciudadanos. En este 2013 la entidad cuenta, en números redondos, con un millón 200 mil habitantes, y obviamente la mayoría se ubica en adolescentes y jóvenes, entre los 10 y los 24 años.

\section{Licenciaturas en Contador Público, Administración de Empresas y Medicina}

Las primeras licenciaturas que se abrieron en el IACT fueron las de Contador Público y Administración de Empresas, que se crearon en la escuela llamada de Contaduría y Administración. El acuerdo del Consejo Directivo del Instituto se dio el 15 de noviembre de 1967, y se iniciaron las actividades a partir del 6 de febrero de 1968. El 13 de enero de 1972, el Consejo aprobó la creación de la carrera de Medicina, la cual inició el 9 de septiembre del mismo año, con un acto solemne de inauguración que se realizó en el Teatro Morelos.

Es importante subrayar que antes de que se aprobara la transformación del Instituto de Ciencias en Universidad Autónoma de Aguascalientes, el grupo fundador se abocó a realizar un estudio sobre diversos aspectos educativos, económicos, políticos y sociales de Aguascalientes, en donde se mostraron conclusiones relevantes que no ponían en duda la imperiosa necesidad de este cambio de una institución del orden medio superior al gran cambio que representaba crear la primera universidad en Aguascalientes. 


\section{Críticas a la universidad tradicional}

Este estudio sirvió para elaborar el primer proyecto del cambio que requería darse en la institución, que tenía un prestigio centenario pero en donde privaban grandes limitaciones en los órdenes académico y económico. El documento se puede considerar como el primer trabajo serio de incursionar en el proceso metodológico de la planeación institucional, herramienta que también sirviera como un elemento de estructuración de los subsecuentes planes de desarrollo que se adoptaron en la universidad para continuar con un modelo de crecimiento ordenado en los aspectos sustantivos como la docencia, la investigación y la difusión de la cultura.

Asimismo, entre las cosas interesantes, se hacía una marcada referencia al modelo de organización de la universidad tradicional, con críticas en lo que hace a los aspectos sociales, como el hecho de estar centralizada en sus servicios o carecer de una verdadera comunicación con su comunidad.

\section{Limitaciones importantes}

En lo que corresponde a la organización académica, se señalaba una marcada deficiencia en la calidad de los estudios; poca flexibilidad; elementos y recursos docentes y académicos dispersos; planes de estudio rígidos, no actualizados, integrados por materias inconexas, incoherentes e innecesariamente prolongados; asimismo, se señalaba que predominaba como principal método de enseñanza la exposición verbal, con docentes de tiempo parcial que enseñaban rutinariamente, en forma conservadora y autócrata; que no ofrecía estímulos para hacer una carrera universitaria, etcétera.

Administrativamente, la universidad tradicional observaba un funcionamiento ineficaz, su base era la improvisación, por lo que caía fácilmente en la irresponsabilidad, el derroche de recursos materiales y humanos; sus administradores carecían también de un espíritu de continuidad por no tener planeación a mediano y largo plazo, orientando la actividad administrativa por juicios superficiales alejados de los objetivos institucionales.

En lo económico, el Estado veía a la universidad como una carga y por ello le subsidiaba de manera insuficiente; la retribución que pagaban los alumnos por el costo de los servicios era injusta y prácticamente simbólica. Políticamente, la universidad permanecía en un desajuste con las autoridades estatales, federales y municipales, propiciado por una marcada confusión en el principio de autonomía.

\section{Se adopta el modelo departamental}

A su vez, se proponía una nueva estructura encaminada hacia un nuevo modelo, que en ese entonces todavía no se definía como el modelo departamental, en donde se destacaban, entre otras características, la autosuficiencia económica; la libertad académica; una comunicación permanente y vital con su comunidad; flexibilidad en su estructura, y finalmente tener una universidad que privilegiara la organización y la planeación.

Indudablemente, la Universidad Autónoma de Aguascalientes presenta diversos ángulos que merecen ser destacados para llegar a consideraciones relevantes que en su tiempo la hicieron ser una institución considerada como diferente a los modelos de organización tradicional que prevalecían, con aportaciones que en su tiempo fueron novedosas y que la hicieron destacar en el marco referencial de las universidades públicas mexicanas. El departamento se convierte en el centro del desarrollo.

\section{Aspectos sociales y políticos}

No estaría de más señalar, aunque sea brevemente, dos hechos coyunturales que favorecieron e impulsaron la creación de la universidad; uno se relaciona con el respaldo social que se le brindó a la naciente institución, y el otro tiene que ver con el aspecto político.

Con el solo anuncio de la creación de la primera universidad en Aguascalientes se desbordó el respaldo popular hacia este proyecto, y no me refiero únicamente al respaldo moral sino a las aportaciones solidarias de tipo económico. En Aguascalientes se dio un acuerdo sobre la necesidad de que surgiera una universidad, incluso un segmento crítico que apareció en el seno de la institución fue en desacuerdo al modelo de universidad que se pretendía adoptar. No es una perogrullada, pero la Universidad Autónoma de Aguascalientes creció en calidad moral gracias a estos apoyos.

Menciono el aspecto político por dos consideraciones que vale tener en cuenta: no olvidemos que en aquellos años en las universidades públicas se tenía memoria de los acontecimientos del 68, y con la llegada del presidente Echeverría se 
cambió la estrategia de enfrentamiento con una política conciliadora, y esto fue un factor determinante para que en su momento el presidente siguiera muy de cerca el nacimiento de la UAA, le otorgara un apoyo extraordinario de 50 millones de pesos para el inicio de la construcción de la Ciudad Universitaria y la promoviera como un modelo interesante; prueba de ello fue la visita del primer rector de la naciente Universidad Autónoma Metropolitana, arquitecto Pedro Ramírez Vázquez, a nuestra casa de estudios para conocer el modelo departamental.

En este contexto tampoco puedo soslayar las gestiones que realizaron a favor de la universidad los políticos aguascalentenses que descollaban en el ámbito nacional, como lo fueron el profesor Enrique Olivares Santana, el ingeniero Miguel Ángel Barberena Vega, el señor Rodolfo Landeros Gallegos, el profesor J. Refugio Esparza Reyes, entre otros.
Mención aparte merece la intervención que tuvieron en ese tiempo las gestiones realizadas por el licenciado Alfonso Rangel Guerra, secretario general ejecutivo de la Asociación Nacional de Universidades e Instituciones de Educación Superior (ANUIES).

La última reflexión, a manera de mea culpa, la hago a los cientos, a los miles de universitarios que se sumaron y respaldaron los primeros impulsos de la universidad, entre alumnos, profesores, administrativos y trabajadores, especialmente a aquellos que hicieron crecer el prestigio del Instituto Autónomo de Ciencias y Tecnología y luego se volcaron en apoyo a la UAA. El prestigio alcanzado por la universidad de nuestros días se debe al cumplimiento en roles y a la responsabilidad que han asumido todos.

Fin

UAA. (2009). Memorias de la UAA y Proyecto Original de la Universidad Autónoma de Aguascalientes. México: UAA.

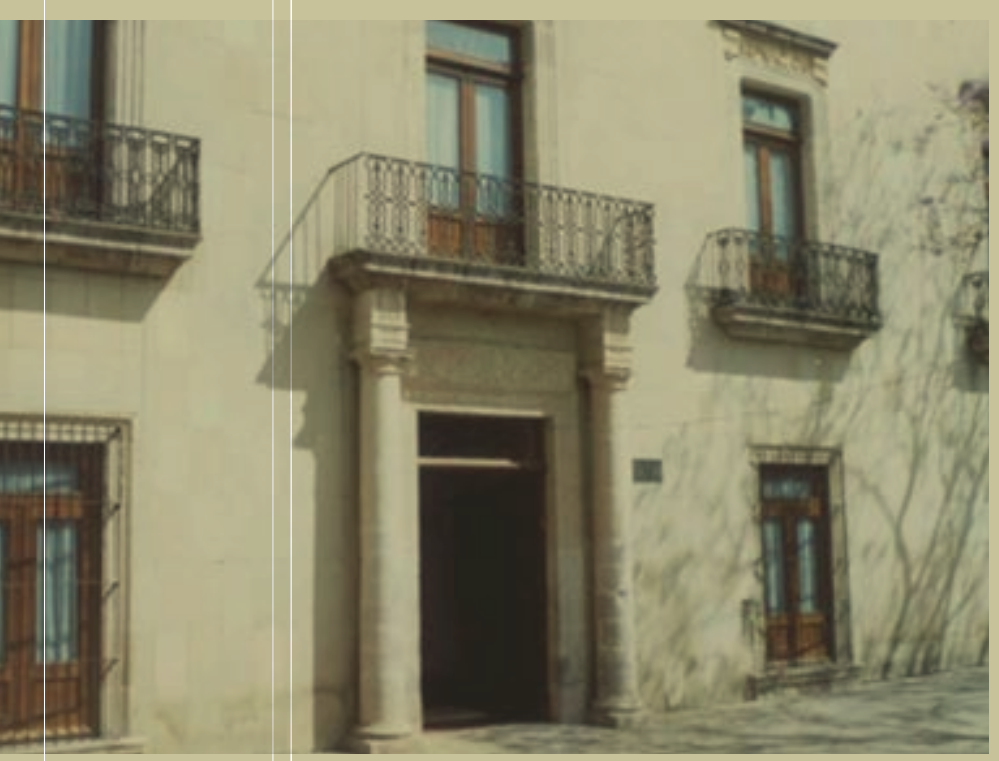

